\title{
Association of lower body mass index with increased glycemic variability in patients with newly diagnosed type 2 diabetes: a cross-sectional study in China
}

\author{
Jian Wang ${ }^{1, *}$, Rengna Yan ${ }^{1, *}$, Juan Wen ${ }^{2,}{ }^{*}$, Xiaocen Kong ${ }^{1}$, Huiqin Li ${ }^{1}$, Peihua Zhou ${ }^{1}$, \\ Honghong Zhu ${ }^{1}$, Xiaofei Su${ }^{1}$ and Jianhua $\mathrm{Ma}^{1}$ \\ ${ }^{1}$ Department of Endocrinology, Nanjing First Hospital, Nanjing Medical University, Nanjing, China \\ 2 Nanjing Maternity and Child Health Care Institute, Nanjing Maternity and Child Health Care Hospital, Obstetrics and \\ Gynecology Hospital Affiliated to Nanjing Medical University, Nanjing, China \\ * These authors have contributed equally to this study \\ Correspondence to: Jianhua Ma, email: majianhua196503@126.com
}

Keywords: body mass index, glycemic variability, continuous glucose monitoring, obesity, postprandial glucose excursion Received: December 14,2016 Accepted:April 03, $2017 \quad$ Published: April 14, 2017

Copyright: Wang et al. This is an open-access article distributed under the terms of the Creative Commons Attribution License 3.0 (CC BY 3.0), which permits unrestricted use, distribution, and reproduction in any medium, provided the original author and source are credited.

\section{ABSTRACT}

Previous studies have indicated that the pathogenesis of diabetes differs between obese and lean patients. We investigated whether newly diagnosed Chinese diabetic patients with different body mass indices (BMIs) have different glycemic variability, and we assessed the relationship between BMI and glycemic variability. This was a cross-sectional study that included 169 newly diagnosed and drug-naïve type 2 diabetic patients (mean age, $51.33 \pm 9.83$ years; 110 men). The clinical factors and results of the 75-g oral glucose tolerance test were all recorded. Glycemic variability was assessed using continuous glucose monitoring. Compared with overweight or obese patients (BMI $\geq 24 \mathrm{~kg} / \mathrm{m}^{2}$ ), underweight or normal-weight patients (BMI < $24 \mathrm{~kg} / \mathrm{m}^{2}$ ) had higher levels of blood glucose fluctuation parameters, particularly in terms of mean amplitude of glycemic excursion (MAGE $6.64 \pm 2.38$ vs. $5.67 \pm 2.05 ; P$ $=0.007$ ) and postprandial glucose excursions (PPGEs) (PPGE at breakfast, $7.72 \pm 2.79$ vs. $6.79 \pm 2.40, P=0.028 ;$ PPGE at lunch, $5.53 \pm 2.70$ vs. $5.07 \pm 2.40, P=0.285 ;$ PPGE at dinner, $5.96 \pm 2.24$ vs. $4.87 \pm 2.50, P=0.008$ ). BMI was negatively correlated with glycemic variability $(r=-0.243, P=0.002)$. On multiple linear regression analyses, BMI $(\beta=-0.231, P=0.013)$ and Insulin Secretion Sensitivity Index-2 $(\beta=-0.204, P$ $=0.048$ ) were two independent predictors of glycemic variability. In conclusion, lower BMI was associated with increased glycemic variability, characterized by elevated PPGEs, in newly diagnosed Chinese type 2 diabetic patients.

\section{INTRODUCTION}

With the rapid economic growth, increase in life expectancy, and changes in lifestyle, the prevalence of diabetes in China has increased significantly in recent decades. In 1980, the prevalence of diabetes in the Chinese population was less than 1\% [1]. In 2010, the national survey [2] estimated the prevalence of diabetes to be $11.6 \%$, which represented up to 113.9 million Chinese adults with diabetes. Diabetes is a major risk factor for cardiovascular disease, which is the leading cause of death in China [3]. Therefore, diabetes has become a major public health problem in the country.

Insulin resistance and impaired insulin secretion are the two main components in the pathophysiology of type 2 diabetes mellitus (T2DM); the contributions of these factors are thought to differ between Chinese and Caucasians [4]. In Caucasians, obesity and its close association with insulin resistance is a major predictor of T2DM, whereas half of T2DM patients in China have normal body weight [5]. Chan et al. [6] reported that the predominant mechanism in lean Chinese diabetic 
patients was impaired insulin secretion, whereas that for obese subjects was insulin resistance. Considering the different pathogenesis of T2DM between obese and lean patients, assessment of the glycemic characteristics in diabetic patients with different body mass index (BMI) is important.

Glycated hemoglobin (HbA1c), which reflected the blood glucose levels over the 2-3 months, has been considered as the gold standard for blood glucose control, but it does not represent the individual's current glycemic status. Alternatively, continuous glucose monitoring (CGM) provides information about the direction, magnitude, duration, frequency, and causes of glucose fluctuation to help physicians and patients detect nocturnal hypoglycemia, dawn phenomenon, and postprandial hyperglycemia [7]. Multiple studies have shown that glucose variability is a potential risk factor for diabetes complications [8-10]. Therefore, it is necessary to evaluate the features of glucose variations in diabetic patients, in addition to the assessment of $\mathrm{HbAlc}$; however, it remains unknown whether newly diagnosed Chinese diabetic

a.

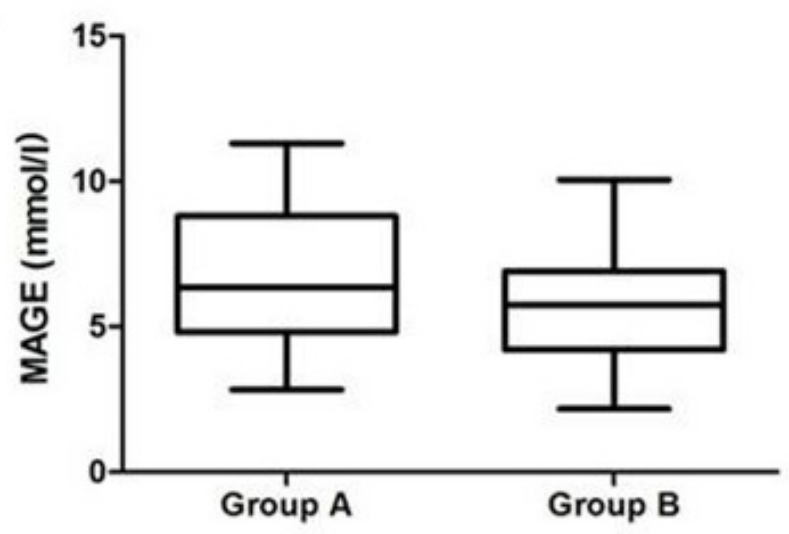

C.

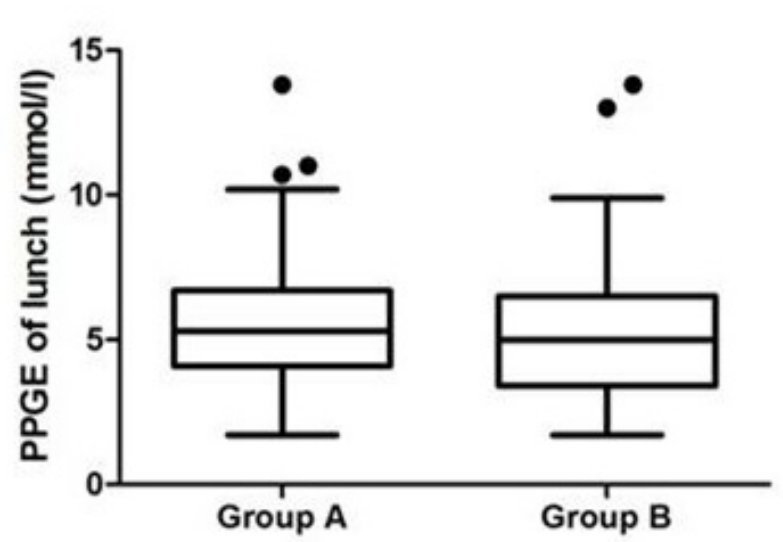

patients with different BMI have different features of glucose variations.

The aim of this study was to determine the differences in the characteristics of glucose fluctuation between underweight or normal-weight patients and overweight or obese patients, as well as the relationship between BMI and glycemic variability in newly diagnosed Chinese T2DM patients.

\section{RESULTS}

\section{Clinical and biochemical characteristics}

The 169 newly diagnosed T2DM patients had a mean age of $51.33 \pm 9.83$ years and were grouped into underweight or normal-weight patients $(n=57)$ and overweight or obese patients $(n=112)$. As shown in Table 1, compared with underweight or normalweight patients, overweight or obese patients were more likely to have higher waist circumference (WC),

b.

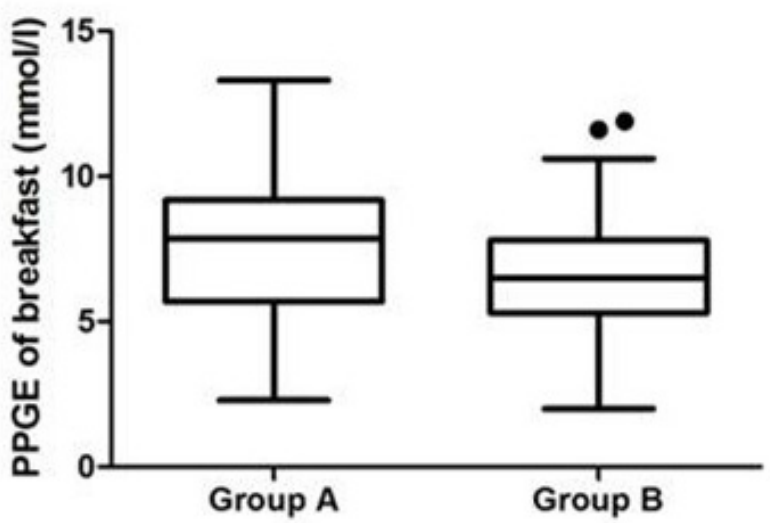

d.

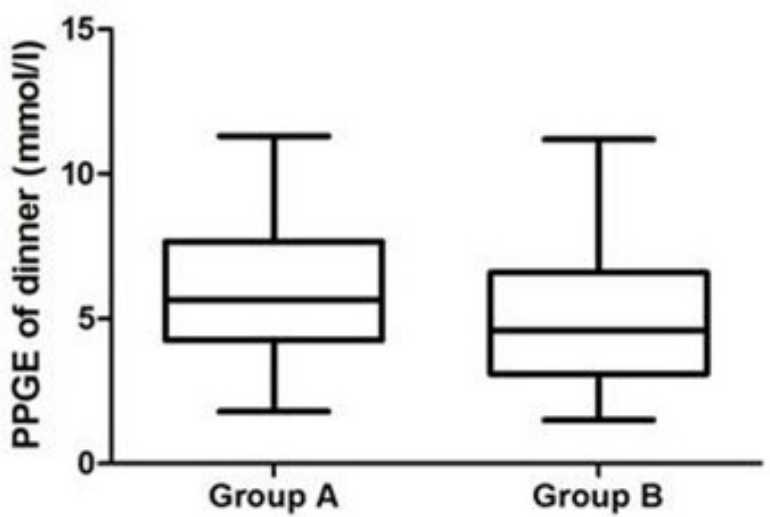

Figure 1: Comparison of MAGE and PPGEs between underweight or normal-weight patients (Group A) and overweight or obese patients (Group B): using box-and-whisker plot. Abbreviations: MAGE, mean amplitude of glycemic excursions; PPGEs, postprandial glucose excursions. The box contained $50 \%$ of all values (from 25 th to 75 th percentile) and was divided by the horizontal bar of the median value (50th percentile). The whiskers showed the remainder of the distribution $(1.5 \times$ Inter Quartile Range). Outliers were shown as dots. 
Table 1: Clinical and biochemical characteristics of the study patients

\begin{tabular}{|c|c|c|c|c|}
\hline Characteristics & $\begin{array}{l}\text { Total } \\
(n=169)\end{array}$ & \begin{tabular}{|ll} 
Underweight & or \\
Normal-weight & \\
$(\mathrm{BMI}<24, n=57)$ & \\
\end{tabular} & $\begin{array}{|ll|}\begin{array}{l}\text { Overweight } \\
\text { Obesity }\end{array} & \text { or } \\
(\text { BMI } \geq 24, n=112) & \\
\end{array}$ & $P$-Value \\
\hline Age (years) & $51.33 \pm 9.83$ & $51.86 \pm 9.53$ & $51.06 \pm 10.02$ & 0.620 \\
\hline Male, n (\%) & $110(65.01 \%)$ & $33(57.89 \%)$ & $77(68.75 \%)$ & 0.162 \\
\hline Current smokers (n (\%)) & $61(36.09 \%)$ & $16(28.07 \%)$ & $45(40.18 \%)$ & 0.121 \\
\hline Current alcohol (n (\%)) & $32(18.93 \%)$ & $9(15.80 \%)$ & $23(20.54 \%)$ & 0.457 \\
\hline Hypertension (n (\%)) & $68(40.24 \%)$ & $15(26.32 \%)$ & $53(47.32 \%)$ & 0.008 \\
\hline Family history of T2DM (n (\%)) & $63(37.28 \%)$ & $18(31.58 \%)$ & $45(40.18 \%)$ & 0.274 \\
\hline BMI $\left(\mathrm{kg} / \mathrm{m}^{2}\right)$ & $25.36 \pm 3.09$ & $22.28 \pm 1.46$ & $26.93 \pm 2.46$ & $<0.001$ \\
\hline $\mathrm{WC}(\mathrm{cm})$ & $87.54 \pm 7.56$ & $81.96 \pm 5.27$ & $90.38 \pm 6.96$ & $<0.001$ \\
\hline ALT $(\mathrm{u} / \mathrm{L})^{*}$ & $25.00(16.00,40.50)$ & $19.00(13.00,33.00)$ & $26.50(19.25,44.75)$ & 0.003 \\
\hline $\operatorname{AST}(\mathrm{u} / \mathrm{L})^{*}$ & $20.00(15.00,28.00)$ & $18.00(14.00,25.00)$ & $20.00(15.00,30.00)$ & 0.080 \\
\hline $\mathrm{TC}(\mathrm{mmol} / \mathrm{l})$ & $5.32 \pm 1.00$ & $5.14 \pm 1.00$ & $5.42 \pm 1.00$ & 0.081 \\
\hline TG $(\mathrm{mmol} / \mathrm{l})^{*}$ & $1.91(1.25,2.68)$ & $1.68(1.18,2.55)$ & $1.98(1.29,2.99)$ & 0.057 \\
\hline HDL-C (mmol/l)* & $1.20(1.01,1.53)$ & $1.34(1.03,1.64)$ & $1.17(1.01,1.50)$ & 0.290 \\
\hline LDL-C (mmol/l) & $2.77 \pm 0.62$ & $2.64 \pm 0.68$ & $2.83 \pm 0.58$ & 0.048 \\
\hline UA (umol/1) & $306.83 \pm 94.06$ & $273.56 \pm 75.85$ & $323.94 \pm 98.34$ & 0.008 \\
\hline Creatinine (umol/l) & $65.36 \pm 15.54$ & $63.34 \pm 15.62$ & $66.34 \pm 15.48$ & 0.248 \\
\hline
\end{tabular}

Abbreviations: BMI, body mass index; WC, waist circumference; ALT, alanine aminotransferase; AST, aspertate aminotransferase; TC, total cholesterol; TG, triglyceride; HDL-C, high-density lipoprotein cholesterol; LDL-C, low-density lipoprotein cholesterol; UA, uric acid.

* ALT, AST, TG and HDL were $\log _{10}$-transformed because of non-normal distribution.

alanine aminotransferase (ALT), low-density lipoprotein cholesterol (LDL-C), uric acid (UA) and proportion of patients with hypertension. All other characteristics were not significantly different between the two groups.

\section{Plasma glucose, plasma insulin, estimates of insulin sensitivity, and pancreatic $\beta$-cell function during oral glucose tolerance test (OGTT)}

The comparisons of glycemic status, insulin sensitivity, and $\beta$-cell function between the groups are summarized in Table 2. Although the levels of HbA1c were not significantly different between the two groups, 120 min blood glucose $\left(\mathrm{BG}_{120 \mathrm{~min}}\right)$ during OGTT was significantly higher in underweight or normal-weight patients than in overweight or obese patients. Compared with overweight or obese patients, underweight or normalweight patients exhibited better insulin sensitivity and poorer pancreatic $\beta$-cell function.

\section{Glycemic variability and CGM measurements}

Table 2 and Figure 1 also show the results of CGM measurements. Compared with overweight or obese patients, underweight or normal-weight patients had significantly higher levels of the mean amplitude of glycemic excursions (MAGE) $(6.64 \pm 2.38 \mathrm{mmol} / \mathrm{L} v s$. $5.67 \pm 2.05 \mathrm{mmol} / \mathrm{L} ; P=0.007)$, standard deviation of blood glucose (SDBG), 24-h mean blood glucose (MBG),
MaxBG, and area under the curve of blood glucose above $10.0 \mathrm{mmol} / \mathrm{L}\left(\mathrm{AUC}_{\text {gluc }>10 \mathrm{mmol} / \mathrm{L}}\right)$. Underweight or normalweight patients had higher levels of postprandial glucose excursions (PPGEs) than overweight or obese patients (PPGE at breakfast, $7.72 \pm 2.79 \mathrm{mmol} / \mathrm{L} v s .6 .79 \pm 2.40$ $\mathrm{mmol} / \mathrm{L}, P=0.028 ; \mathrm{PPGE}$ at lunch, $5.53 \pm 2.70 \mathrm{mmol} / \mathrm{L}$ vs. $5.07 \pm 2.40 \mathrm{mmol} / \mathrm{L}, P=0.285 ;$ PPGE at dinner, $5.96 \pm$ $2.24 \mathrm{mmol} / \mathrm{L}$ vs. $4.87 \pm 2.50 \mathrm{mmol} / \mathrm{L}, P=0.008)$.

\section{Relationship between BMI and glycemic characteristics}

Upon evaluating the correlation between BMI and glycemic characteristics (Table 3), we observed that BMI was positively correlated with homeostasis model assessment for islet beta $\beta$-cell function index (HOMA- $\beta$ ), insulin secretion sensitivity index-2 (ISSI-2) and homeostasis model assessment for insulin resistance (HOMA-IR); whereas negatively correlated with Matsuda Insulin Sensitivity Index (Matsuda ISI), MAGE $(r=$ $-0.243, P=0.002$, Figure 2), 24h-MBG, SDBG, $\mathrm{AUC}_{\text {gluc }}$ $>10 \mathrm{mmol} / \mathrm{L}$, MaxBG.

\section{Relationship between glycemic variability and other variables}

Furthermore, correlation analyses (Table 4) revealed that MAGE was negatively correlated with BMI, Matsuda ISI, HOMA- $\beta$, and ISSI- 2 , but was positively correlated 
Table 2: Insulin sensitivity, $\beta$-cell function and glucose fluctuations of the study patients

\begin{tabular}{|c|c|c|c|c|}
\hline Characteristics & \begin{tabular}{|l|} 
Total \\
$(n=169)$
\end{tabular} & \begin{tabular}{|l|} 
Underweight or Normal-weight \\
$(\mathrm{BMI}<\mathbf{2 4}, n=57)$
\end{tabular} & \begin{tabular}{|l|}
$\begin{array}{l}\text { Overweight or Obesity } \\
(\mathrm{BMI} \geq 24, n=112)\end{array}$ \\
\end{tabular} & $P$-Value \\
\hline OGTT-BG 0min (mmol/1) & $10.22 \pm 2.20$ & $10.11 \pm 2.45$ & $10.28 \pm 2.05$ & 0.696 \\
\hline OGTT-BG 30min (mmol/l) & $15.82 \pm 2.82$ & $15.92 \pm 2.81$ & $15.76 \pm 2.84$ & 0.757 \\
\hline OGTT-BG 120min (mmol/l) & $21.41 \pm 4.42$ & $22.79 \pm 4.78$ & $20.58 \pm 3.99$ & 0.008 \\
\hline OGTT-Insulin $0 \mathrm{~min}(\mu \mathrm{IU} / \mathrm{ml})^{*}$ & $6.53(4.06,9.21)$ & $5.43(3.23,7.45)$ & $7.23(4.99,10.37)$ & 0.004 \\
\hline OGTT-Insulin 30min $(\mu \mathrm{IU} / \mathrm{ml}) *$ & $13.55(9.25,20.25)$ & $11.45(8.24,15.89)$ & $15.16(9.76,22.46)$ & 0.020 \\
\hline OGTT-Insulin 120min $(\mu \mathrm{IU} / \mathrm{ml}) *$ & $23.31(14.86,34.76)$ & $19.21(11.45,26.60)$ & $25.62(17.30,38.47)$ & 0.047 \\
\hline HbA1c (\%) & $8.98 \pm 1.24$ & $9.17 \pm 1.28$ & $8.89 \pm 1.22$ & 0.172 \\
\hline HOMA-IR* & $2.76(1.89,4.54)$ & $2.56(1.59,3.41)$ & $3.23(2.32,4.75)$ & 0.003 \\
\hline Matusuda ISI* & $79.48(56.52,108.07)$ & $92.09(72.50,156.31)$ & $73.96(49.67,99.45)$ & 0.003 \\
\hline HOMA- $\beta *$ & $19.96(12.60,31.34)$ & $14.61(11.16,26.60)$ & $24.19(13.58,32.93)$ & 0.035 \\
\hline Insulinogenic index* & $1.22(0.51,2.49)$ & $1.02(0.58,2.01)$ & $1.48(0.50,2.70)$ & 0.444 \\
\hline ISSI-2* & $92.67(69.79,110.73)$ & $78.13(55.07,99.18)$ & $100.88(82.98,112.34)$ & 0.002 \\
\hline 24h-MBG (mmol/l) & $11.18 \pm 2.24$ & $11.67 \pm 2.58$ & $10.93 \pm 2.01$ & 0.016 \\
\hline MAGE (mmol/l) & $6.00 \pm 2.21$ & $6.64 \pm 2.38$ & $5.67 \pm 2.05$ & 0.007 \\
\hline $\mathrm{SDBG}(\mathrm{mmol} / \mathrm{l})$ & $2.41 \pm 0.89$ & $2.64 \pm 0.98$ & $2.29 \pm 0.82$ & 0.017 \\
\hline $\mathrm{AUC}_{\mathrm{gluc}>10 \mathrm{mmol} / 1}(\mathrm{mmol} / 1 \text { per day })^{*}$ & $1.50(0.50,3.10)$ & $2.20(0.90,4.00)$ & $1.35(0.50,2.90)$ & 0.038 \\
\hline $\operatorname{MaxBG}(\mathrm{mmol} / \mathrm{l})$ & $16.85 \pm 3.39$ & $17.59 \pm 3.59$ & $16.47 \pm 3.23$ & 0.043 \\
\hline MinBG (mmol/1) & $6.80 \pm 2.05$ & $7.00 \pm 2.32$ & $6.69 \pm 1.90$ & 0.359 \\
\hline Pre-breakfast BG (mmol/l) & $9.14 \pm 2.34$ & $9.35 \pm 2.69$ & $9.02 \pm 2.14$ & 0.398 \\
\hline PPBG peak-breakfast (mmol/l) & $16.26 \pm 3.48$ & $17.07 \pm 3.62$ & $15.83 \pm 3.34$ & 0.030 \\
\hline PPGE of breakfast (mmol/l) & $7.11 \pm 2.56$ & $7.72 \pm 2.79$ & $6.79 \pm 2.40$ & 0.028 \\
\hline Pre-lunch BG (mmol/l) & $9.48 \pm 2.74$ & $9.80 \pm 3.12$ & $9.32 \pm 2.53$ & 0.328 \\
\hline PPBG peak-lunch $(\mathrm{mmol} / \mathrm{l})$ & $14.71 \pm 3.41$ & $15.34 \pm 3.44$ & $14.40 \pm 3.37$ & 0.115 \\
\hline PPGE of lunch (mmol/l) & $5.22 \pm 2.50$ & $5.53 \pm 2.70$ & $5.07 \pm 2.40$ & 0.285 \\
\hline Pre-dinner BG (mmol/l) & $9.07 \pm 2.67$ & $9.49 \pm 2.72$ & $8.84 \pm 2.63$ & 0.145 \\
\hline PPBG peak-dinner (mmol/l) & $14.33 \pm 3.43$ & $15.45 \pm 3.71$ & $13.72 \pm 3.12$ & 0.002 \\
\hline PPGE of dinner $(\mathrm{mmol} / \mathrm{l})$ & $5.26 \pm 2.46$ & $5.96 \pm 2.24$ & $4.87 \pm 2.50$ & 0.008 \\
\hline
\end{tabular}

Abbreviations: OGTT, oral glucose tolerance test; BG, blood glucose; HbA1c, glycated hemoglobin; HOMA-IR, homeostasis model assessment for insulin resistance; Matusuda ISI, Matsuda Insulin Sensitivity Index; HOMA- $\beta$, homeostasis model assessment for islet $\beta$-cell function index; ISSI-2, insulin secretion sensitivity index-2; 24h-MBG, 24-h mean blood glucose;

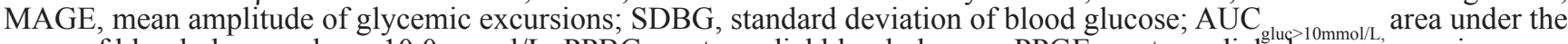
curve of blood glucose above $10.0 \mathrm{mmol} / \mathrm{L}$; PPBG, postprandial blood glucose; PPGE, postprandial glucose excursion.

* OGTT-Insulin 0min, OGTT-Insulin 30min, OGTT-Insulin 120min, HOMA-IR, Matusuda ISI, HOMA- $\beta$, Insulinogenic index, ISSI-2, and $\mathrm{AUC}_{\text {gluc }>10 \mathrm{mmol} / \mathrm{L}}$ were $\log _{10}$-transformed because of non-normal distribution.

with $\mathrm{HbA1c}, 24 \mathrm{~h}-\mathrm{MBG}, \mathrm{SDBG}, \mathrm{AUC}_{\text {gluc }>10 \mathrm{mmol} / \mathrm{L}}$, MaxBG, and PPGEs; however, MAGE was not associated with HOMA-IR and insulinogenic index.

\section{Multiple linear regression analysis with glycemic variability (MAGE) as the dependent variable}

On multivariate regression analyses using models 1-4 (Table 5), BMI emerged as an independent variable associated with MAGE. As shown in model 3, BMI and $\mathrm{HbA1c}$ were two independent predictors of MAGE, but Matsuda ISI was not. Addition of the covariate ISSI2 in model 2 revealed that BMI and ISSI- 2 were two independent predictors (model 4).

\section{DISCUSSION}

In this study, we evaluated the glycemic variations in newly diagnosed Chinese T2DM patients with different BMI. We observed that underweight or normal-weight patients had poorer pancreatic $\beta$-cell function, and higher levels of blood glucose fluctuation parameters (MAGE, SDBG, and PPGEs) than overweight or obese patients. Moreover, our results indicated that BMI and pancreatic $\beta$-cell function were significantly associated with glycemic variability (MAGE). These findings suggested that decreased pancreatic $\beta$-cell function may contribute to increased glucose fluctuation in newly diagnosed T2DM individual with relatively low BMI. To the best of our knowledge, this was the first study to investigate the association between BMI and glycemic variability in this population. 
A cross-sectional study [11] including 53 individuals with normal glucose tolerance (NGT), 53 subjects with impaired glucose regulation (IGR) and 56 T2DM patients showed that MAGE were significantly higher in IGR subjects $(3.33 \pm 1.55 \mathrm{mmol} / \mathrm{L})$ and T2DM patients $(4.82$ $\pm 1.70 \mathrm{mmol} / \mathrm{L})$ than NGT subjects $(2.74 \pm 1.18 \mathrm{mmol} / \mathrm{L})$. Another cross-sectional study [12] about glycemic variability on 434 healthy Chinese adults reported that the 95th percentiles of MAGE and SDBG were 3.86 and $1.40 \mathrm{mmol} / \mathrm{L}$, respectively. Therefore, MAGE $<3.9$ $\mathrm{mmol} / \mathrm{L}$ and SDBG $<1.4 \mathrm{mmol} / \mathrm{L}$ are recommended as the normal reference ranges for glycemic variability in Chinese adults. In our populations studied, MAGE and SDBG were $6.00 \pm 2.21 \mathrm{mmol} / \mathrm{L}$ and $2.41 \pm 0.89 \mathrm{mmol} / \mathrm{L}$, which were much higher than the normal reference ranges for glycemic variability.

A series of previous studies [13] have revealed that HbA1c positively associate with glycemic variability in patients with T2DM. In order to exclude the influence of HbA1c on glycemic variability, we chose newlydiagnosed T2DM inpatients as study subjects. Based on our results, the levels of $\mathrm{HbA} 1 \mathrm{c}$ in underweight or normalweight patients were comparable to those in overweight or obese patients, but underweight or normal-weight patients had poorer pancreatic $\beta$-cell function and higher glycemic variability parameters. In agreement with our results, a cross-sectional study [6] on 521 Chinese diabetic subjects reported that BMI correlated positively with fasting C-peptide $(r=0.250, P<0.001)$; underweight patients had the lowest $\mathrm{C}$-peptide, whereas overweight patients had the highest $\mathrm{C}$-peptide. In addition, a series of previous studies [14-16] indicated that $\beta$-cell dysfunction was related to increased glycemic variability. A cross-sectional study [14] of 59 patients with T2DM showed that postprandial $\beta$-cell function (a model-based method from plasma C-peptide and plasma glucose during a mixed meal test) was an independent contributor to glycemic variability (MAGE). Similarly, decreased oral disposition index on OGTT was associated with glycemic variability parameters across the range of glucose tolerance, from normal to pre-diabetes to T2DM [15]. Moreover, a prospective study [16] on 61 diabetic patients demonstrated that improvement of $\beta$-cell function, reflected as ISSI-2, was the main contributor for the decrease in glycemic variability. Corresponding with these studies, our results revealed that $\beta$-cell function was negatively associated with glycemic variability (MAGE). Therefore, we assumed that decline of $\beta$-cell function may be the main cause of the increased glycemic variability in newly diagnosed T2DM with relatively low BMI.

A large number of clinical studies [17-19] have indicated that postprandial hyperglycemia was independently related to cardiovascular disease, microvascular events, cognitive dysfunction, and cancer. Increased PPGEs lead to oxidative stress, inflammation, and impaired endothelial function, all of which are involved in the microvascular and macrovascular complications of diabetes [20]. Therefore, evaluation of postprandial blood glucose (PPBG) and PPGEs are particularly meaningful in patients with diabetes. In our study, we found that underweight or normal-weight patients had higher peak levels of PPBG and PPGEs than overweight or obese patients. The quantity of carbohydrate has been shown to be a consistent predictor of PPBG concentrations [21]. In addition, the type or source of carbohydrate also plays an important role in regulating PPBG levels. Wolever and Mehling [22] examined the

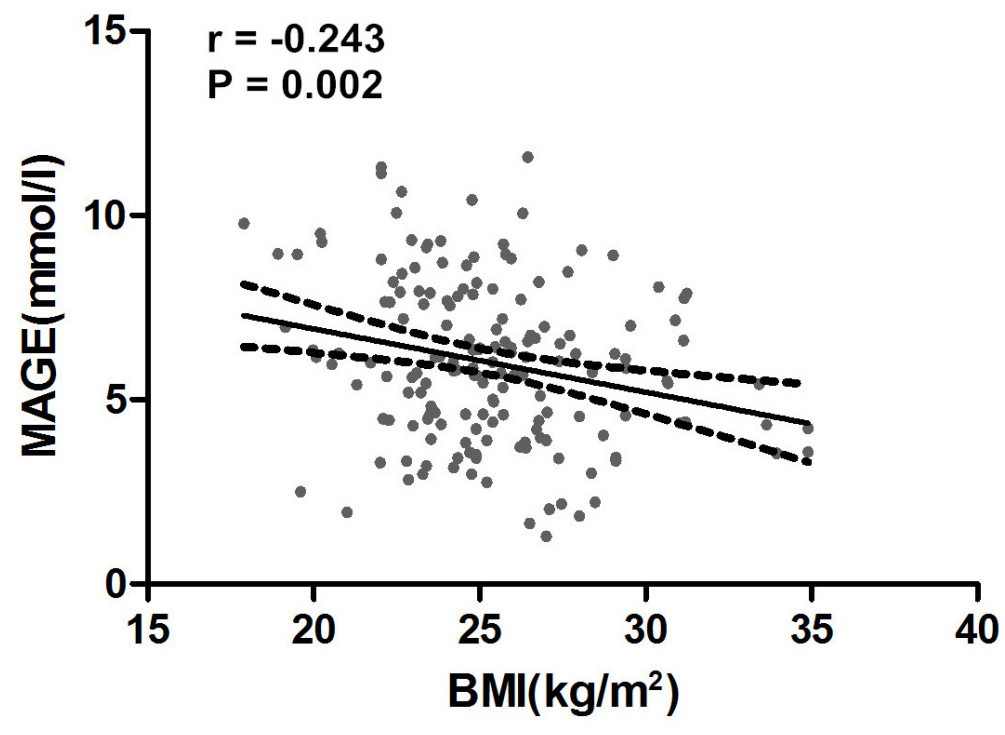

Figure 2: The relation between BMI and MAGE. Abbreviations: BMI, body mass index; MAGE, mean amplitude of glycemic excursions. Linear relation between BMI and MAGE was observed. The correlation coefficient was $-0.243(P=0.002)$. 
Table 3: Linear correlation analysis of BMI and glycemic characteristics

\begin{tabular}{|c|c|c|}
\hline Variables & $\mathbf{R}$ & $P$-value \\
\hline OGTT-BG 120min & -0.228 & 0.013 \\
\hline $\log _{10}$ OGTT- Insulin 0min* & 0.370 & $<0.001$ \\
\hline $\log _{10}$ OGTT- Insulin 30min* & 0.311 & 0.001 \\
\hline $\log _{10}$ OGTT- Insulin 120min* & 0.223 & 0.016 \\
\hline $\log _{10}$ HOMA-IR* & 0.368 & $<0.001$ \\
\hline $\log _{10}$ Matusuda ISI* & -0.373 & $<0.001$ \\
\hline $\log _{10}$ HOMA- $\beta *$ & 0.304 & 0.001 \\
\hline $\log _{10}$ Insulinogenic index* & 0.179 & 0.053 \\
\hline $\log _{10}$ ISSI-2* & 0.244 & 0.008 \\
\hline 24h-MBG (mmol/l) & -0.205 & 0.008 \\
\hline MAGE (mmol/l) & -0.243 & 0.002 \\
\hline SDBG (mmol/l) & -0.190 & 0.014 \\
\hline $\log _{10} \mathrm{AUC}_{\text {gluc }>10 \mathrm{mmol} / \mathrm{L}} *$ & -0.240 & 0.002 \\
\hline MaxBG (mmol/l) & -0.182 & 0.019 \\
\hline
\end{tabular}

Abbreviations: OGTT, oral glucose tolerance test; BG, blood glucose; HOMA-IR, homeostasis model assessment for insulin resistance; Matusuda ISI, Matsuda Insulin Sensitivity Index; HOMA- $\beta$, homeostasis model assessment for islet $\beta$-cell function index; ISSI-2, insulin secretion sensitivity index-2; 24h-MBG, 24-h mean blood glucose; MAGE, mean amplitude of glycemic excursions; SDBG, standard deviation of blood glucose; $\mathrm{AUC}_{\text {gluc }>10 \mathrm{mmol} / \mathrm{L} \text {, }}$ area under the curve of blood glucose above 10.0 $\mathrm{mmol} / \mathrm{L}$.

$\mathrm{R}$, correlation coefficient

* OGTT-Insulin 0min, OGTT-Insulin 30min, OGTT-Insulin 120min, HOMA-IR, Matusuda ISI, HOMA- $\beta$, Insulinogenic index, ISSI-2, and $\mathrm{AUC}_{\text {gluc }>10 \mathrm{mmol} / \mathrm{L}}$ were $\log _{10}$-transformed because of non-normal distribution.

long-term effect of varying the type of dietary carbohydrate on PPBGs in 34 subjects with impaired glucose tolerance. Their results showed that PPBGs were lowered by the same amount on high-carbohydrate, low-glycemic index diets when compared with values in subjects on the high-carbohydrate, high-glycemic index diet. However, whether there is a relationship between glycemic index or glycemic load of diets and the development of diabetes or obesity has not been determined [23-27]. To exclude the effect of diet on PPBG fluctuations, our patients ate the standardized meals with consistent compositions and sources during the CGM period. In addition, the increase of PPBG could have also been affected by impaired postprandial insulin secretion, accompanied by increased glucagon secretion and decreased hepatic and peripheral glucose uptake [28]. In our study, we found that underweight or normal-weight patients had poorer $\beta$-cell function compared with overweight or obese patients; this could be the main cause of the higher levels of PPBG and PPGEs in lower BMI patients. The levels of hormones such as glucagon and incretins, which contribute to the regulation of PPGEs, were not assessed in our study. In the future, we will evaluate whether the levels of these hormones are different between the two groups.

In our study, we found that the PPGE was higher at breakfast than at lunch or dinner in both groups. In agreement with our results, Sylvia et al. [20] have demonstrated that for the same carbohydrate intake, PPGE was 1.60 times greater at breakfast than at lunch and was 1.35 times greater at breakfast than at dinner. Another study [29] showed that the AUC 1-4 h after a meal was significantly larger after breakfast compared with the values after lunch and dinner. The higher PPGE after breakfast may be due to the "dawn phenomenon", which resulted in increased hepatic glucose output and decreased glucose utilization in the morning.

Some limitations of this study deserve comments. First, we estimated insulin secretion and insulin sensitivity based on the OGTT, not by the "gold standard" test, which is the glucose-clamp technique; however, clamping is expensive and not easily feasible in a relatively large-scale study, and we believe that proxy measures are reliable. A previous study [30] has indicated that Matsuda ISI was positively related to clamp value $(r=0.77, P<0.001)$. ISSI-2 has been directly validated against the disposition index from the intravenous glucose tolerance test and has been used to measure $\beta$-cell function in several previous studies $[16,31]$. Second, we combined overweight and obese patients in one study group because of the relatively small sample size of obese patients. Third, hormones (i.e., incretin and glucagon) that may contribute to the regulation of PPGEs and be relevant to glycemic variability were not assessed in our study.

Despite these potential limitations, this study had several advantages. First, glycemic variability was assessed by CGM in a relatively large population. Second, 
Table 4: Linear correlation analysis of MAGE and other variables

\begin{tabular}{|c|c|c|}
\hline Variables & $\mathbf{R}$ & $P$-value \\
\hline BMI & -0.243 & 0.002 \\
\hline $\mathrm{HbA} 1 \mathrm{c}$ & 0.268 & $<0.001$ \\
\hline $\log _{10}$ Matusuda ISI* & -0.239 & 0.009 \\
\hline $\log _{10}$ HOMA- $\beta *$ & -0.218 & 0.018 \\
\hline $\log _{10}$ ISSI-2* & -0.303 & 0.001 \\
\hline 24h-MBG & 0.414 & $<0.001$ \\
\hline SDBG & 0.835 & $<0.001$ \\
\hline $\log _{10} \mathrm{AUC}_{\mathrm{gluc}>1 \mathrm{mmmolh}} *$ & 0.385 & $<0.001$ \\
\hline MaxBG & 0.675 & $<0.001$ \\
\hline PPGE of breakfast & 0.582 & $<0.001$ \\
\hline PPGE of lunch & 0.444 & $<0.001$ \\
\hline PPGE of dinner & 0.572 & $<0.001$ \\
\hline
\end{tabular}

Abbreviations: MAGE, mean amplitude of glycemic excursions; BMI, body mass index; HbAlc, glycated hemoglobin; Matusuda ISI, Matsuda Insulin Sensitivity Index; HOMA- $\beta$, homeostasis model assessment for islet $\beta$-cell function index; ISSI-2, insulin secretion sensitivity index-2; 24h-MBG, 24-h mean blood glucose; SDBG, standard deviation of blood glucose; $\mathrm{AUC}_{\mathrm{gluc}>10 \mathrm{mmo} / \mathrm{L}}$ area under the curve of blood glucose above $10.0 \mathrm{mmol} / \mathrm{L}$; PPGE, postprandial glucose excursion. $\mathrm{R}$, correlation coefficient

*Matusuda ISI, HOMA- $\beta$, ISSI-2 and $\mathrm{AUC}_{\text {gluc }>10 \mathrm{mmol} / \mathrm{L}}$ were $\log _{10}$-transformed because of non-normal distribution.

to minimize confounding factors, we selected newly diagnosed and drug-naïve T2DM as study subjects who were controlled for consistent physical activity and diets during the CGM period.

In this study on Chinese patients with newly diagnosed T2DM, patients with relatively low BMI had increased glycemic variability characterized by elevated PPGEs. Moreover, poor $\beta$-cell function might be the main contributory factor associated with increased glycemic variability in patients with lower BMI. Our data suggested that improvement of $\beta$-cell function and reduction of postprandial hyperglycemia could be important therapeutic targets in controlling glycemic variability in T2DM patients with lower BMI. A prospective study is warranted to validate whether underweight or normalweight patients with T2DM are more likely to develop diabetes complications than overweight or obese patients with T2DM in China.

\section{MATERIALS AND METHODS}

\section{Study patients}

Newly diagnosed T2DM patients who visited the Department of Endocrinology of Nanjing First Hospital between June 2014 and November 2015 were enrolled in this study. Inclusion criteria were age $>18$ years and newly diagnosed and drug-naïve T2DM. Exclusion criteria were as follows: 1) presence of liver or renal dysfunction (liver enzyme levels $>2.5$-fold the upper normal limit or serum creatinine $>1.3$-fold the upper normal limit, respectively); 2) use of medications or drugs that may alter glucose metabolism (e.g., thyroid hormones, glucocorticoids, and thiazide diuretics); 3) presence of islet autoantibodies, such as glutamic acid decarboxylase autoantibody, islet cell antibody, insulin autoantibody or insulinoma-associated protein 2 autoantibody; 4) presence of acute or chronic infectious disease, pregnancy or lactation, or a history of cancer. Finally, 169 patients (110 men and 59 women, mean age of $51.33 \pm 9.83$ years) were analyzed in this study. This study was approved by the ethics committee of Nanjing First Hospital and all study patients gave written informed consent. The methods were carried out in accordance with the Declaration of Helsinki guidelines, including any relevant details.

\section{Clinical and laboratory assessments}

The social-behavioral information, family and medical histories, and health-related habits were checked by the study physicians. Smoking or alcohol consumption was defined as daily cigarette or alcohol use, respectively, for at least 12 months, regardless of the amount. Anthropometric measurements, including height, weight, and WC; systolic blood pressure (SBP); and diastolic blood pressure (DBP) were determined by experienced nurses. WC was measured at the midpoint between the lower border of the rib cage and the iliac crest. BMI was calculated as weight divided by the square of height $(\mathrm{kg} /$ $\mathrm{m}^{2}$ ). According to the Working Group on Obesity in China in 2003 [32], we classified patients as underweight or normal (BMI $<24 \mathrm{~kg} / \mathrm{m}^{2}$ ) and overweight or obese (BMI $\geq$ $24 \mathrm{~kg} / \mathrm{m}^{2}$ ). Peripheral blood pressure was measured using 
Table 5: Multiple linear regression models of MAGE (dependent variable)

\begin{tabular}{|c|c|c|}
\hline Model & Standardized $\beta$ & $P$-value \\
\hline \multicolumn{3}{|l|}{ Model 1: } \\
\hline Age & -0.077 & 0.328 \\
\hline Sex & 0.015 & 0.849 \\
\hline Family history of T2DM & 0.097 & 0.212 \\
\hline BMI & -0.237 & 0.003 \\
\hline \multicolumn{3}{|l|}{ Model 2: Model 1 + HbA1C } \\
\hline Age & -0.021 & 0.789 \\
\hline Sex & 0.015 & 0.877 \\
\hline Family history of T2DM & 0.100 & 0.187 \\
\hline BMI & -0.206 & 0.007 \\
\hline $\mathrm{HbA1C}$ & 0.249 & 0.001 \\
\hline \multicolumn{3}{|c|}{ Model 3: Model $2+\log _{10}$ Matusuda Index } \\
\hline Age & 0.048 & 0.611 \\
\hline Sex & 0.013 & 0.890 \\
\hline Family history of T2DM & -0.002 & 0.980 \\
\hline BMI & -0.206 & 0.029 \\
\hline $\mathrm{HbA1C}$ & 0.249 & 0.041 \\
\hline $\log _{10}$ Matusuda Index* & 0.112 & 0.288 \\
\hline \multicolumn{3}{|l|}{ Model 4: Model 2 + ISSI-2 } \\
\hline Age & 0.070 & 0.750 \\
\hline Sex & -0.036 & 0.686 \\
\hline Family history of T2DM & -0.027 & 0.764 \\
\hline BMI & -0.231 & 0.013 \\
\hline $\mathrm{HbA1C}$ & 0.130 & 0.214 \\
\hline $\log _{10}$ ISSI-2* & -0.204 & 0.048 \\
\hline
\end{tabular}

Abbreviations: MAGE, mean amplitude of glycemic excursions; BMI, body mass index; HbAlc, glycated hemoglobin; Matusuda ISI, Matsuda Insulin Sensitivity Index; ISSI-2, insulin secretion sensitivity index-2.

MAGE is regarded as the dependent variable and independent variables in model 1 included age, sex, family history of T2DM, and BMI. Furthermore, analyses were performed with the addition of the following covariates: HbAlc (model 2); HbAlc and Matsuda ISI (model 3); HbA1c and ISSI-2 (model 4).

$\beta$, regression coefficient.

*Matusuda ISI and ISSI-2 were $\log _{10}$-transformed because of non-normal distribution.

brachial sphygmomanometry and was recorded as the mean of three measured readings. Patients with a history of hypertension or abnormally high arterial blood pressure ( $\mathrm{SBP} \geq 140 \mathrm{mmHg}$ or $\mathrm{DBP} \geq 90 \mathrm{mmHg}$ ) were considered as hypertension.

After at least $10 \mathrm{~h}$ of overnight fast, all study patients were subjected to a 75-g OGTT and blood samples were collected at 0,30 , and $120 \mathrm{~min}$. Plasma blood glucose levels were measured using hexokinase method. Serum insulin concentrations were measured using radioimmunoassay (Beijing Technology Company; Beijing, China). Insulin sensitivity was evaluated by HOMA-IR [HOMA-IR = fasting blood insulin (FBI) $(\mathrm{mU} / \mathrm{L}) \times$ fasting blood glucose $(\mathrm{FBG})(\mathrm{mmol} / \mathrm{L}) / 22.5]$ [33] and Matsuda ISI [Matsuda ISI $=10,000 /(\mathrm{FBG} \times$ FBI $\times$ mean glucose during OGTT $\times$ mean insulin during
OGTT $)^{1 / 2}$ [34]. $\beta$-cell function was estimated by HOMA- $\beta$ $[$ HOMA- $\beta=20 \times$ FBI / $(\mathrm{FBG}-3.5)]$ [33]; insulinogenic index $[\Delta$ insulin30 / $\Delta$ glucose $30=($ insulin30 - FBI $) /$ (glucose30 - FBG)] [35] and ISSI-2 [36]. Area under the insulin curve $\left(\mathrm{AUC}_{\mathrm{ins}}\right)$ and area under the glucose curve $\left(\mathrm{AUC}_{\mathrm{gluc}}\right)$ were calculated using the trapezoidal rule [37], ISSI-2 $=\left(\mathrm{AUC}_{\mathrm{ins}} / \mathrm{AUC}_{\mathrm{gluc}}\right) \times$ Matsuda ISI. Plasma total cholesterol (TC), triglyceride (TG), high-density lipoprotein cholesterol (HDL-C), LDL-C, ALT, aspartate aminotransferase (AST), blood urea nitrogen (BUN), creatinine and UA were measured with an auto-analyzer (Modular E170; Roche, Mannheim, Germany). HbA1c levels were determined using high-performance liquid chromatography (BIO-RAD Company; Hercules, CA, USA).

After collection of clinical and laboratory data, a 
CGM device was placed in all study patients for 3 days. The CGM sensor was inserted on day 0 at 4:00pm 5:00pm. and was removed on day 4 at 8:00am - 9:00am. Every day during the CGM period, capillary blood glucose was checked at least four times to calibrate the glucose values of the CGM sensor. During the period of CGM sensor monitoring, all patients were required to refrain from both structured and recreational physical activity. Patients were provided with a standardized diet, which was designed to ensure a total daily energy intake of 105 $\mathrm{KJ} / \mathrm{kg} /$ day consisting of $55 \%$ of energy from carbohydrate, $18 \%$ from protein, and $27 \%$ from fat. The foods were divided into three equal portions consumed by patients at 07:00am - 8:00am, 11:30am - 12:30am and 5:30pm $6: 30 \mathrm{pm}$. The CGM indices adopted in this study included MAGE, 24-h MBG, SDBG, $\mathrm{AUC}_{\text {gluc }>10 \mathrm{mmol} / \mathrm{L}}$, and PPGEs. PPGE was calculated as the peak glucose value after meals minus the glucose level at the beginning of each meal [11].

\section{Statistical analysis}

All statistical analyses were conducted using SPSS 17.0 for Windows (Chicago, IL, USA). Continuous variables were tested for normality of distribution by one-sample Kolmogorov-Smirnov tests, and natural log transformations of abnormally distributed variables were used as necessary. Variables with normal distribution were expressed as mean \pm standard deviation, those with abnormal distribution were expressed as median (interquartile range), and categorical variables were expressed as proportion. After assessing the homogeneity of variances, we evaluated the differences in clinical, biochemical values, insulin sensitivity, $\beta$-cell function, and glucose fluctuations between underweight or normalweight patients and overweight or obese patients using Student's $t$-test, Welch's $t$-test or chi-square test, as appropriate. The associations between BMI, glucose variability (MAGE) and other various parameters were assessed by Pearson correlation analyses. Multiple linear regression analyses of MAGE (dependent variable) were performed with model 1, which consisted of the following variables: age, sex, family history of T2DM and BMI. Furthermore, analyses were performed with the addition of the following covariates: HbAlc (model 2); HbA1c and Matsuda ISI (model 3); HbA1c and ISSI-2 (model 4) The statistical tests were two-sided and a P-value of $<0.05$ was considered statistically significant.

\section{Authors' contributions}

J.W. and J.M. contributed in design, statistical analysis and drafting of the manuscript. J.W. contributed in statistical analysis. R.Y., X.K., H.L., P.Z., H.Z. and X.S. contributed in data collection and manuscript drafting. J.M. supervised the study.

\section{CONFLICTS OF INTEREST}

The authors declare no conflicts of interest.

\section{FUNDINGS}

This study was supported by the grants from Jiangsu Provincial Department of Science, Technology Project (BL2014010), Scientific and Technological Development Foundation of Nanjing medical university (2015NJMU052).

\section{REFERENCES}

1. A mass survey of diabetes mellitus in a population of 300,000 in 14 provinces and municipalities in China. [Article in Chinese] Zhonghua Nei Ke Za Zhi. 1981; 20:678-683.

2. Xu Y, Wang L, He J, Bi Y, Li M, Wang T, Wang L, Jiang Y, Dai M, Lu J, Xu M, Li Y, Hu N, et al. Prevalence and control of diabetes in Chinese adults. JAMA. 2013; 310:948-959.

3. He J, Gu D, Wu X, Reynolds K, Duan X, Yao C, Wang J, Chen CS, Chen J, Wildman RP, Klag MJ, Whelton PK. Major causes of death among men and women in China. $\mathrm{N}$ Engl J Med. 2005; 353:1124-1134.

4. Chan JC, Malik V, Jia W, Kadowaki T, Yajnik CS, Yoon $\mathrm{KH}, \mathrm{Hu}$ FB. Diabetes in Asia: epidemiology, risk factors, and pathophysiology. JAMA. 2009; 301:2129-2140.

5. Chiu M, Austin PC, Manuel DG, Shah BR, Tu JV. Deriving ethnic-specific BMI cutoff points for assessing diabetes risk. Diabetes Care. 2011; 34:1741-1748.

6. Chan WB, Tong PC, Chow CC, So WY, Ng MC, Ma RC, Osaki R, Cockram CS, Chan JC. The associations of body mass index, C-peptide and metabolic status in Chinese Type 2 diabetic patients. Diabet Med. 2004; 21:349-353.

7. Klonoff DC. Continuous glucose monitoring: roadmap for 21 st century diabetes therapy. Diabetes Care. 2005; 28:1231-1239.

8. Jin HY, Lee KA, Park TS. The impact of glycemic variability on diabetic peripheral neuropathy. Endocrine. 2016; 53:643-648.

9. Wang X, Zhao X, Dorje T, Yan H, Qian J, Ge J. Glycemic variability predicts cardiovascular complications in acute myocardial infarction patients with type 2 diabetes mellitus. Int J Cardiol. 2014; 172:498-500.

10. Fleischer J, Lebech Cichosz S, Hoeyem P, Laugesen E, Loegstrup Poulsen P, Sandahl Christiansen J, Tarnow L, Hansen TK. Glycemic variability is associated with reduced cardiac autonomic modulation in women with type 2 diabetes. Diabetes Care. 2015; 38:682-688.

11. Wang C, Lv L, Yang Y, Chen D, Liu G, Chen L, Song Y, 
He L, Li X, Tian H, Jia W, Ran X. Glucose fluctuations in subjects with normal glucose tolerance, impaired glucose regulation and newly diagnosed type 2 diabetes mellitus. Clin Endocrinol (Oxf). 2012; 76:810-815.

12. Zhou J, Li H, Ran X, Yang W, Li Q, Peng Y, Li Y, Gao X, Luan X, Wang W, Jia W. Establishment of normal reference ranges for glycemic variability in Chinese subjects using continuous glucose monitoring. Med Sci Monit. 2011; 17:CR9-13.

13. Fang FS, Li ZB, Li CL, Tian H, Li J, Cheng XL. Influence of glycemic variability on the HbA1c level in elderly male patients with type 2 diabetes. Intern Med. 2012; 51:31093113.

14. Kohnert KD, Augstein P, Zander E, Heinke P, Peterson K, Freyse EJ, Hovorka R, Salzsieder E. Glycemic variability correlates strongly with postprandial beta-cell dysfunction in a segment of type 2 diabetic patients using oral hypoglycemic agents. Diabetes Care. 2009; 32:1058-1062.

15. Chen $\mathrm{T}, \mathrm{Xu} F, \mathrm{Su} J \mathrm{~B}$, Wang $\mathrm{XQ}$, Chen JF, Wu G, Jin $\mathrm{Y}$, Wang XH. Glycemic variability in relation to oral disposition index in the subjects with different stages of glucose tolerance. Diabetol Metab Syndr. 2013; 5:38.

16. Kramer CK, Choi H, Zinman B, Retnakaran R. Glycemic variability in patients with early type 2 diabetes: the impact of improvement in beta-cell function. Diabetes Care. 2014; 37:1116-1123.

17. Aryangat AV, Gerich JE. Type 2 diabetes: postprandial hyperglycemia and increased cardiovascular risk. Vasc Health Risk Manag. 2010; 6:145-155.

18. Monnier L, Mas E, Ginet C, Michel F, Villon L, Cristol JP, Colette C. Activation of oxidative stress by acute glucose fluctuations compared with sustained chronic hyperglycemia in patients with type 2 diabetes. JAMA. 2006; 295:1681-1687.

19. Cavalot F, Petrelli A, Traversa M, Bonomo K, Fiora E, Conti M, Anfossi G, Costa G, Trovati M. Postprandial blood glucose is a stronger predictor of cardiovascular events than fasting blood glucose in type 2 diabetes mellitus, particularly in women: lessons from the San Luigi Gonzaga Diabetes Study. J Clin Endocrinol Metab. 2006; 91:813-819.

20. Franc S, Dardari D, Peschard C, Riveline JP, Biedzinski M, Boucherie B, Petit C, Requeda E, Mistretta F, VarroudVial M, Charpentier G. Can postprandial blood glucose excursion be predicted in type 2 diabetes? Diabetes Care. 2010; 33:1913-1918.

21. Gannon MC, Nuttall FQ, Westphal SA, Fang S, Ercan-Fang N. Acute metabolic response to high-carbohydrate, highstarch meals compared with moderate-carbohydrate, lowstarch meals in subjects with type 2 diabetes. Diabetes Care. 1998; 21:1619-1626.

22. Wolever TM, Mehling C. Long-term effect of varying the source or amount of dietary carbohydrate on postprandial plasma glucose, insulin, triacylglycerol, and free fatty acid concentrations in subjects with impaired glucose tolerance. Am J Clin Nutr. 2003; 77:612-621.

23. Bhupathiraju SN, Tobias DK, Malik VS, Pan A, Hruby A, Manson JE, Willett WC, Hu FB. Glycemic index, glycemic load, and risk of type 2 diabetes: results from 3 large US cohorts and an updated meta-analysis. Am J Clin Nutr. 2014; 100:218-232.

24. Mosdol A, Witte DR, Frost G, Marmot MG, Brunner EJ. Dietary glycemic index and glycemic load are associated with high-density-lipoprotein cholesterol at baseline but not with increased risk of diabetes in the Whitehall II study. Am J Clin Nutr. 2007; 86:988-994.

25. Rossi M, Bosetti C, Talamini R, Lagiou P, Negri E, Franceschi S, La Vecchia C. Glycemic index and glycemic load in relation to body mass index and waist to hip ratio. Eur J Nutr. 2010; 49:459-464.

26. Mendez MA, Covas MI, Marrugat J, Vila J, Schroder H. Glycemic load, glycemic index, and body mass index in Spanish adults. Am J Clin Nutr. 2009; 89:316-322.

27. Lau C, Toft U, Tetens I, Richelsen B, Jorgensen T, BorchJohnsen K, Glumer C. Association between dietary glycemic index, glycemic load, and body mass index in the Inter99 study: is underreporting a problem? Am J Clin Nutr. 2006; 84:641-645.

28. Rizza RA. Pathogenesis of fasting and postprandial hyperglycemia in type 2 diabetes: implications for therapy. Diabetes. 2010; 59:2697-2707.

29. Cichosz SL, Fleischer J, Hoeyem P, Laugesen E, Poulsen PL, Christiansen JS, Ejskjaer N, Hansen TK. Assessment of postprandial glucose excursions throughout the day in newly diagnosed type 2 diabetes. Diabetes Technol Ther. 2013; 15:78-83.

30. Lorenzo C, Haffner SM, Stancakova A, Kuusisto J, Laakso M. Fasting and OGTT-derived measures of insulin resistance as compared with the euglycemichyperinsulinemic clamp in nondiabetic Finnish offspring of type 2 diabetic individuals. J Clin Endocrinol Metab. 2015; 100:544-550.

31. Retnakaran R, Qi Y, Goran MI, Hamilton JK. Evaluation of proposed oral disposition index measures in relation to the actual disposition index. Diabet Med. 2009; 26:1198-1203.

32. Wang H, Du S, Zhai F, Popkin BM. Trends in the distribution of body mass index among Chinese adults, aged 20-45 years (1989-2000). Int J Obes (Lond). 2007; 31:272278.

33. Oh TJ, Lim S, Kim KM, Moon JH, Choi SH, Cho YM, Park KS, Jang H, Cho NH. One-hour postload plasma glucose concentration in people with normal glucose homeostasis predicts future diabetes mellitus: a 12-year communitybased cohort study. Clin Endocrinol (Oxf). 2016.

34. Matsuda M, DeFronzo RA. Insulin sensitivity indices obtained from oral glucose tolerance testing: comparison with the euglycemic insulin clamp. Diabetes Care. 1999; 22:1462-1470. 
35. Sluiter WJ, Erkelens DW, Reitsma WD, Doorenbos H. Glucose tolerance and insulin release, a mathematical approach I. Assay of the beta-cell response after oral glucose loading. Diabetes. 1976; 25:241-244.

36. Kramer CK, Choi H, Zinman B, Retnakaran R. Determinants of reversibility of beta-cell dysfunction in response to short-term intensive insulin therapy in patients with early type 2 diabetes. Am J Physiol Endocrinol Metab. 2013; 305:E1398-1407.
37. Wolever TM, Jenkins DJ. The use of the glycemic index in predicting the blood glucose response to mixed meals. Am J Clin Nutr. 1986; 43:167-172. 